\title{
The Deep-Breath Test as a Diagnostic Maneuver for White-Coat Effect in Hypertensive Patients
}

\author{
Federico A. Augustovski, MD, MSc, Cecilia B. Calvo, MD, Matías Deprati, MD, and \\ Gabriel Waisman, MD
}

Background: The white-coat effect is a common phenomenon in hypertensive patients, and there is no current useful office test to detect it.

Methods: This was a cross-sectional study. We evaluated the deep-breath maneuver at the office as a diagnostic test of the white-coat effect. Participants included 83 adult patients with uncontrolled office hypertension. We measured sensitivity, specificity, likelihood ratios of different cutoff points, area under receiver operating characteristic (ROC) curve, and 95\% confidence intervals. The reference standard used was 24-hour ambulatory blood pressure monitoring.

Results: We included 73 patients [mean age, $58.7 \pm 9.5$ years (mean \pm SD); $55 \%$ women]. The prevalence of white-coat effect was $62 \%$. Comparing patients with white-coat effect versus those without, the deep-breath test resulted in a mean systolic blood pressure decrease of 17.8 and $10.9 \mathrm{~mm} \mathrm{Hg}(P<$ $.001)$ and a mean diastolic decrease of 6.6 and $5.4 \mathrm{~mm} \mathrm{Hg}$, respectively $(P=$ not significant). The area under the ROC curve of systolic blood pressure change was 0.69 ( $95 \%$ confidence interval, 0.57 to $0.81)$. Interobserver agreement was very good.

Conclusions: The deep-breath test can be a helpful maneuver for the detection of white-coat effect. It has no major adverse effects and it may help avoid overtreatment and unnecessary further testing procedures. (J Am Board Fam Pract 2004;17:184-9.)

High blood pressure is one of the most frequent causes for office visits, and it has a major impact on overall morbidity and mortality. ${ }^{1,2}$ Although great progress has been made regarding hypertension management, diagnosis and treatment are still suboptimal. Current management of high blood pressure is characterized by underdiagnosis, misdiagnosis, undertreatment, overtreatment, and misuse of medications. ${ }^{3-5}$ Causes for overtreatment include the incorrect diagnosis of hypertension, as in the case of white-coat hypertension, and the incorrect diagnosis of refractory hypertension, as in the case of white-coat effect.

White-coat response is defined as higher blood pressure at the doctor's office than in an ambulatory setting. It is observed in both ambulatory nor-

Submitted, revised, 1 December 2003.

From the Unidad de Medicina Familiar y Preventiva, Hospital Italiano de Buenos Aires, Buenos Aires, Argentina (FA, CC, MD); and Unidad de Hipertensión Arterial, Buenos Aires, Argentina (GW). Address correspondence to Federico A. Augustovski, Unidad de Medicina Familiar y Preventiva, Hospital Italiano de Buenos Aires, Perón 4272 (1199), Buenos Aires, Argentina (e-mail: faugus@post. harvard.edu).

This work was supported by Unidad de Medicina Familiar y Preventiva, Unidad de Hipertensión Arterial, Hospital Italiano de Buenos Aires, Argentina. motensive patients (white-coat hypertension) and in sustained hypertension (usually called white-coat phenomenon or white-coat effect). Therefore, white-coat effect is a clinically relevant finding even among patients with treated hypertension, ${ }^{6-10}$ and it may persist on subsequent visits, which suggests that it is a specific response to the clinical situation. ${ }^{11}$

This unusual increase in office blood pressure in patients with treated hypertension can be interpreted as refractory hypertension. Clinicians may then increase the antihypertensive drug doses or add further medication, increasing costs and side effects. $^{12}$

Studies performed in hypertensive patients report prevalences ranging from $35 \%$ to $73 \% .6,7,9,13$ Recently, Myers and Reeves ${ }^{13}$ found that $70 \%$ to $73 \%$ of treated patients in primary care showed a white-coat response, and $31 \%$ to $32 \%$ exhibited a "marked white coat effect."

One study showed that white-coat effect is present in patients with treated and nontreated hypertension. ${ }^{14}$ Variables associated with whitecoat effect are female sex and increasing age and body mass index. It is much more significantly observed for systolic than for diastolic blood pres- 
sure, and it is more frequent in white persons. ${ }^{7,8,12,15}$ Twenty-four hour ambulatory blood pressure monitoring (ABPM) is currently the diagnostic test of choice for its detection. ${ }^{16-20}$ Breathing rhythm has an effect on blood pressure. A small study done by Yoshihara et $\mathrm{al}^{21}$ showed that the deep-breath test (deep breathing 5 times for a minute in seated position) was useful in identifying white-coat hypertension. In a preliminary study, we found that deep breathing led to an initial decrease in blood pressure in patients with drug-treated hypertension. Some clinical trials showed a decrease in blood pressure in hypertensive patients with device-guided slow breathing. ${ }^{2-25}$ Basic science research in animals also supports this response. ${ }^{26}$

The detection of the white-coat effect by a simple test done at the office could play an important role in hypertension care and lead to a more rational management of patients with hypertension. We intended to determine whether the change in blood pressure after deep breathing-the deep-breath test-is different between hypertensive patients with white-coat effect and those without it, and whether it can be a useful diagnostic test for the detection of this prevalent phenomenon in the office.

\section{Methods}

\section{Overview}

Noncontrolled hypertensive patients were administered a standard deep-breath test by their usual primary care doctors at a routine office visit. Within 2 days this was followed by 24-hour ABPM with interpretation by technicians blinded to the results of the deep-breath test.

\section{Sample, Setting, Power Calculation}

The Hospital Italiano de Buenos Aires Advisory Committee on Ethics in Human Experimentation approved the study. This primary care-based study was conducted within a university-affiliated HMO serving 70,000 patients. We included adult patients with persistently uncontrolled office hypertension $(>140 / 90 \mathrm{~mm} \mathrm{Hg})$. Pregnant women and patients having their first 2 visits to their primary care physician were excluded. We also excluded patients with suspected secondary hypertension. The study was conducted between September 2000 and May 2001.
For the deep-breath test to achieve $80 \pm 15 \%$ specificity and sensitivity, we needed at least 28 patients in the least prevalent group. Because we estimated that $40 \%$ of the population would not have the white-coat effect, we aimed to recruit a total sample size of 70 patients.

\section{Deep-Breath Test and ABPM}

All office readings were done in standard conditions and were performed in the sitting position with calibrated mercury sphygmomanometers (Baumanometer; WA Baum Co., Inc., Copiague, $\mathrm{NY)}$ and appropriate cuff sizes.

After taking two readings before the test (basal readings), the deep-breath maneuver was done by asking the patient to breath deeply for 30 seconds. Blood pressure was recorded immediately after the test, and then after 2 minutes. We used the 24-hour ambulatory blood pressure monitoring (SpaceLab 90207) as the reference standard for ambulatory blood pressure. It was performed within 48 hours of the deep-breath test. Primary care physicians were blind to the ambulatory blood pressure monitoring, and the ambulatory blood pressure monitoring technician was also blind to the deep-breath test results. We only report patients who had an adequate ambulatory blood pressure study with more than $80 \%$ of successful readings.

Although there is variability in the definition of white-coat effect, and both systolic (SBP) and diastolic blood pressures (DBP) are typically used, we defined it in our primary analysis as the decrease of $10 \%$ or more between baseline office and daytime ambulatory SBP.

To evaluate whether the observed difference in blood pressure after the deep-breath test was an effect of time or regression to the mean, we undertook a pilot study comparing the effect of the deepbreath test versus rechecking blood pressure after 5 minutes with the patient in the sitting position. In the 20 patients evaluated in each pilot group, the difference was significant for SBP drop (16.8 \pm 9.1 $\mathrm{mm} \mathrm{Hg}$ for the deep-breath test vs $4.2 \pm 3.1 \mathrm{~mm}$ $\mathrm{Hg}$ in the 5 -minute recheck group, $P<.001)$, but not for DBP drop $(6.7 \pm 5.2$ vs $5.0 \pm 3.9 \mathrm{~mm} \mathrm{Hg})$. With this pilot test, we can be confident that the effect of the deep-breath test on SBP was not explained by regression to the mean or just waiting 5 minutes for another reading. We also analyzed the inter-observer agreement in a subsample of 15 patients. 


\section{Statistical Considerations}

We evaluated the operating characteristics of different cutoff points, or different responses to the deep-breath test, to detect the white-coat effect. We calculated the area under the receiver operating characteristic (ROC) curve, sensitivity, specificity, and likelihood ratios positive and negative for the different cutoff values of blood pressure change. We used the $\kappa$ statistic to evaluate interobserver agreement. We used logistic regression analysis adjusting for age, sex, and office blood pressure to evaluate independent factors associated with the white-coat effect. All these measurements were 2 -sided, with $95 \%$ confidence limits. We used descriptive statistics to present our sample characteristics. Data were analyzed with STATA version 6.0 (STATA Corporation, College Station, TX).

\section{Results \\ Patient Sample}

Of the 83 subjects who completed the 24-hour ABPM, 73 had more than $80 \%$ adequate readings and were included for further analyses; excluded patients had similar age, sex, treatment, and basal blood measurements. The mean number of ABPM readings was 112 , approximately 5 per hour.

The 73 patients included in the sample for analysis had a mean age of $58.7 \pm 9.5$ years (mean \pm $\mathrm{SD})$; $45 \%$ were men. Most were receiving monotherapy, and almost a third took 2 or more drugs. Medications included $\beta$-adrenergic receptor blockers in $40 \%$, thiazides in $36 \%$, angiotensin-converting enzyme inhibitors in $27 \%$, calcium channel blockers in $16 \%$, and angiotensin receptor blockers in $5 \%$ of the patients. Other demographic characteristics and risk factors are shown in Table 1.

\section{Deep-Breath Test Results and White-Coat Effect Interobserver Agreement}

In a subsample of 15 patients, there was very good interobserver agreement between the physicians in defining a positive response for SBP (defined as a decrease of $>15 \mathrm{~mm} \mathrm{Hg}$ of $\mathrm{SBP}) . \kappa=0.81$ ( $\mathrm{SE}=$ $0.2721 ; P=.001)$. The agreement was not as good for diastolic readings.

The deep-breath test reduced SBP by $15 \mathrm{~mm}$ $\mathrm{Hg}$ and DBP by about $6 \mathrm{~mm} \mathrm{Hg}$ (Table 2). We found a prevalence of white-coat effect of $62 \%$ (45 of 73) in this mostly female primary care population. As reported elsewhere, ${ }^{7}$ the white-coat effect
Table 1. Patient Demographic and Clinical Characteristics $(\mathbf{n}=73)$

\begin{tabular}{lc}
\hline Variable & Value* $^{*}$ \\
\hline Mean age (SD) & $58.7(9.5)$ \\
Female [N (\%)] & $40(55 \%)$ \\
Obesity [N (\%)] & $35(48 \%)$ \\
Dyslipidemia [N (\%)] & $24(33 \%)$ \\
Smokers [N (\%)] & $9(12 \%)$ \\
Diabetes [N (\%)] & $7(10 \%)$ \\
Coronary artery disease [N (\%)] & $5(7 \%)$ \\
Therapy & $14 \%$ \\
$\quad$ Non-Pharmacologic only & $54 \%$ \\
Monotherapy & $32 \%$ \\
Two drugs & $7 \%$ \\
Three or more drugs & \\
\hline
\end{tabular}

* Percentage values are rounded to the nearest integer.

was more frequent in women than in men $(72 \%$ vs $47 \% ; P=0.03$ ), in older people (subjects with white-coat effect had a mean age of 60.2 vs 56.2 in those without it; $P=0.08$ ), and in subjects with higher office SBP (persons with white-coat effect had a mean office SBP of 158.7 vs. $146.9 \mathrm{~mm} \mathrm{Hg}$ in those without it, $P<.001$ ). Only 2 patients reported mild dizziness, which did not interfere with the maneuver completion. No other adverse effect was reported.

Although there was no significant difference in DBP change, the decrease in SBP was almost twice as large in patients with white-coat effect compared with those without it. This difference was highly significant (Table 3).

\section{Deep-Breath Test Operating Characteristics}

The area under the ROC curve showed that SBP change was a good diagnostic test for white-coat effect (area under the ROC curve 0.69, [95\% confidence interval (CI), 0.57 to 0.81$]$ ) (Table 4). The area under the ROC curve in the subgroup of patients treated nonpharmacologically seemed to be similar than the subjects with medication $(0.67$ vs 0.70$)$.

For example, if SBP change with deep-breath test is less than $5 \mathrm{~mm} \mathrm{Hg}$, sensitivity for white-coat effect is $87 \%$, specificity is $18 \%$, and post-test odds of white-coat effect are reduced by one third. If SBP change is $25 \mathrm{~mm} \mathrm{Hg}$ or more, sensitivity decreases to $29 \%$, specificity increases to $96 \%$, and the post-test odds of white-coat effect increase by a factor of 8 . 
Table 2. Blood Pressure Response to the Deep-Breath Test in 73 Patients

\begin{tabular}{lccr}
\hline Variable & $\begin{array}{c}\text { Before } \\
\text { Deep Breathing }\end{array}$ & $\begin{array}{c}\text { Immediately after } \\
\text { Deep Breathing }\end{array}$ & $\begin{array}{r}\text { Two Minutes after } \\
\text { Deep Breathing }\end{array}$ \\
\hline Systolic blood pressure & 154.8 (SD 14) & 139.6 (SD 14) & 144.1 (SD 15) \\
Diastolic blood pressure & 98.6 (SD 9) & 92.5 (SD 10) & 94.9 (SD 10) \\
\hline
\end{tabular}

The area under the ROC curve for DBP was 0.53 (95\% CI, 0.38 to 0.67 ), showing that it is uninformative. In a logistic regression analysis adjusting for age, sex, and office blood pressure, the only variable significantly associated with whitecoat effect was SBP change after deep-breath test.

\section{Discussion}

In this primary care-based study, we show important new findings that could potentially influence daily practice: SBP change after the deep-breath test was useful to detect white-coat effect in hypertensive patients. It is performed at the office in less than 2 minutes, the results are immediate, and it has no known adverse effects.

Deep-breath test could be a useful office test to rule in white-coat effect in hypertensive patients. If SBP drop is $20 \mathrm{~mm} \mathrm{Hg}$ or more, the post-test odds of disease almost quadruples; if the drop is $25 \mathrm{~mm}$

Table 3. Deep-Breath Test Responses in Patients with and without White-Coat Effect

\begin{tabular}{llll}
\hline & \multicolumn{2}{l}{ White Coat Effect } & \\
\cline { 2 - 3 } & $\begin{array}{c}\text { Present } \\
(\mathrm{n}=45)\end{array}$ & $\begin{array}{c}\text { Absent } \\
(\mathrm{n}=28)\end{array}$ & $P$ \\
\hline $\begin{array}{l}\text { Systolic blood pressure decrease } \\
{[\text { Mean mm Hg (SD) }]}\end{array}$ & $17.8(10.6)$ & $10.9(8.1)$ & .005 \\
$\begin{array}{l}\text { Diastolic blood pressure decrease } \\
{[\text { Mean mm Hg (SD)] }}\end{array}$ & $6.6(6.9)$ & $5.4(5.2)$ & $\mathrm{NS}^{*}$ \\
\hline
\end{tabular}

* NS, not significant.

Table 4. Deep-Breath Test Operating Characteristics for SBP Drop

\begin{tabular}{lcccc}
\hline & & & \multicolumn{2}{c}{ Likelihood Ratio } \\
\cline { 4 - 5 } Cutoff Value & Sensitivity & Specificity & Positive & Negative \\
\hline$>5 \mathrm{~mm} \mathrm{Hg}$ & 86.7 & 17.9 & 1.05 & 0.7 \\
$>10 \mathrm{~mm} \mathrm{Hg}$ & 80.0 & 35.7 & 1.2 & 0.6 \\
$>15 \mathrm{~mm} \mathrm{Hg}$ & 60.0 & 71.43 & 2.1 & 0.6 \\
$>20 \mathrm{~mm} \mathrm{Hg}$ & 51.1 & 85.7 & 3.6 & 0.6 \\
$>25 \mathrm{~mm} \mathrm{Hg}$ & 28.9 & 96.4 & 8.1 & 0.7 \\
\hline
\end{tabular}

$\mathrm{Hg}$ or more, the odds increase by a factor of 8 . If, on the other hand, one is intending to rule out white-coat effect, deep-breath test would not be as useful (shown by the modest likelihood ratio negatives).

Our study adds information to the growing literature on the effects of slow and deep breathing and its effects on blood pressure. ${ }^{21-25}$ One contradicting piece of evidence, probably as a result of the inclusion of patients with untreated mild to moderate hypertension, is the Yoshihara study, ${ }^{21}$ which found DBP but not SBP change useful to detect white-coat hypertension.

Our study had several strengths: it was conducted by 20 different primary care physicians in real office setting to reflect daily practice, the deepbreath test was independent of and blind to the standard 24-hour ABPM, and it had an adequate spectrum of patients. Our results could have been more precise if only one observer had performed the test in a highly standardized environment, but the external validity would have been jeopardized.

\section{Limitations}

Because physicians could have been aware of the effect of the deep-breath test, they might have biased the SBP decrease. It is highly unlikely that, not knowing the ambulatory blood pressure result and white-coat effect state, they could have evaluated the blood pressure change differently in patients who were later categorized as having whitecoat effect or not.

Another potential limitation is that $14 \%$ of our patients were taking no antihypertensive medications, and they could have white-coat hypertension without ambulatory hypertension. An exploratory analysis, although underpowered, showed no difference in deep-breath test behavior between medicated and nonmedicated patients. This may suggest that the deep-breath test could be a useful maneuver for white-coat hypertension as well. Different drugs may exert different effects regarding breath-test response. However, our study has no 
power to detect differential effects on breath-test responses among different drugs.

Because the white-coat effect can lead to overtreatment of high blood pressure, ${ }^{27}$ its detection could favor the selective treatment of sustained and refractory hypertension. ${ }^{12}$ One study showed that adjustment of antihypertensive treatment based on ABPM instead of conventional blood pressure led to less intensive drug treatment with preservation of blood pressure control and inhibition of left ventricular enlargement but did not reduce the overall costs of treatment. ${ }^{28}$ High blood pressure readings in the office are the basis of the evidence that hypertension increases cardiovascular risk, and treatment decisions in the management of hypertension are mostly guided by office blood pressure readings. To date, no study has shown the safety of withholding treatment in patients with office hypertension and normal ambulatory blood pressure. The common belief that it is unnecessary to treat office hypertension in patients with "normal" ambulatory blood pressures, although attractive, is unwarranted. ${ }^{29}$ A question that remains unanswered is the clinical relevance of the white-coat effect itself. ${ }^{29,30}$

Taking this context into account, the deepbreath test could have important clinical implications. First, it may reduce overtreatment in that therapy could be guided by post-deep-breath test measurements, which are more closely related to ambulatory pressure; second, as a consequence of avoiding overtreatment, patients health-related quality of life could be improved substantially; third, this test could also lead to less resource utilization, not only in drugs but also in 24-hour ambulatory monitoring. For example, if a cut-off point of $20 \mathrm{~mm} \mathrm{Hg}$ is used, $50 \%$ of patients with white-coat effect would be detected and ambulatory monitoring potentially avoided; fourth, although formal economic evaluations are needed, deep-breath test may also reduce total economic burden in hypertension management.

In conclusion, deep-breath test can be a helpful maneuver for the detection of white-coat effect. It has no major adverse effects, and it may help avoid overtreatment and unnecessary further testing procedures.

We are really grateful to Mario I. Cámera, whose clinical knowledge and intuition led to the idea of the deep-breath test; to Fernando Rubinstein and Lorena Allemandi for their thoughtful review of the manuscript; and to Silvia Espósito, the ambulatory blood pressure monitoring technician.

\section{References}

1. Collins R, Peto R, MacMahon S, et al. Blood pressure, stroke, and coronary heart disease. Part 2, Short-term reductions in blood pressure: overview of randomised drug trials in their epidemiological context. Lancet 1990;335:827-38.

2. Five-year findings of the hypertension detection and follow-up program. I. Reduction in mortality of persons with high blood pressure, including mild hypertension. Hypertension Detection and Followup Program Cooperative Group. 1979. JAMA 1997; 277:157-66.

3. Trilling JS, Froom J. The urgent need to improve hypertension care. Arch Fam Med 2000;9:794-801.

4. Chobanian AV, Bakris GL, Black HR, et al.; National Heart, Lung, and Blood Institute Joint National Committee on Prevention, Detection, Evaluation, and Treatment of High Blood Pressure; National High Blood Pressure Education Program Coordinating Committee. The seventh report of the Joint National Committee on Prevention, Detection, Evaluation, and Treatment of High Blood Pressure: the JNC 7 report [published erratum appears in JAMA 2003;290:197]. JAMA 2003; 289:2560-72.

5. Guidelines Committee. 2003 European Society of Hypertension-European Society of Cardiology guidelines for the management of arterial hypertension. J Hypertens 2003;21:1011-53.

6. Myers MG. The white coat effect in treated hypertension. Blood Press Monit 1996;1:247-9.

7. MacDonald MB, Laing GP, Wilson MP, Wilson TW. Prevalence and predictors of white-coat response in patients with treated hypertension. CMAJ 1999;161:265-9.

8. Mansoor GA, McCabe EJ, White WB. Determinants of the white coat effect in hypertensive subjects. J Hum Hypertens 1996;10:87-92.

9. Little P, Barnett J, Barnsley L, Marjoram J, Fitzgerald-Berron A, Mant D. Comparison of agreement between different measures of blood pressure in primary care and daytime ambulatory blood pressure. BMJ 2002;325:254-9.

10. Myers MG, Reeves RA. White coat effect in treated hypertensive patients: sex differences. J Hum Hypertens 1995;9:729-33.

11. Mancia G, Bertinieri G, Grassi G, Parati G, Pomidossi G, Ferrari A. Effects of blood-pressure measurement by the doctor on patient's blood pressure and heart rate. Lancet 1983;2:695-8.

12. Amado P, Vasconcelos N, Santos I, Almeida L, Nazare J, Carmona J. Arterial hypertension difficult to control in the elderly patient. The significance of the white coat effect. Rev Port Cardiol 1999;18:897906. 
13. Myers MG, Reeves RA. White coat phenomenon in patients receiving antihypertensive therapy. Am J Hypertens 1991;4:844-9.

14. Pannarale G, Collauto F, Serafini GL, Serafini G, Campa PP. Influence of antihypertensive therapy on the white coat effect. Minerva Cardioangiol 1994;42: 169-72.

15. Gualdiero P, Niebauer J, Addison C, Clark SJ, Coats AJ. Clinical features, anthropometric characteristics, and racial influences on the white coat effect in a single centre cohort of 1553 consecutive subjects undergoing routine ambulatory blood pressure monitoring. Blood Press Monit 2000;5:53-7.

16. O'Brien E, Coats A, Owens P, Petrie J, Padfield PL, Littler WA, et al. Use and interpretation of ambulatory blood pressure monitoring: recommendations of the British Hypertension Society. BMJ 2000;320: 1128-34.

17. Staessen JA, Beilin L, Parati G, Waeber B, White $W$. Task force IV: clinical use of ambulatory blood pressure monitoring. Participants of the 1999 Consensus Conference on Ambulatory Blood Pressure Monitoring. Blood Press Monit 1999;4:319-31.

18. Pickering T. Recommendations for the use of home (self) and ambulatory blood pressure monitoring. American Society of Hypertension Ad Hoc Panel. Am J Hypertens 1996;9:1-11.

19. The sixth report of the Joint National Committee on Prevention, Detection, Evaluation, and Treatment of High Blood Pressure. Arch Intern Med 1997;157: 2413-46.

20. Comas A, Gonzalez-Nuevo JP, Plaza F, et al. The evaluation of the hypertensive patient via self-measured blood pressure at home. Aten Primaria 1998; 22:142-8.

21. Yoshihara K, Fukui T, Osawa H, et al. Deep breath- ing test (DBT) in predicting white coat hypertension. Fukuoka Igaku Zasshi 1993;84:395-401.

22. Rosenthal T, Alter A, Peleg E, Gavish B. Deviceguided breathing exercises reduce blood pressure: ambulatory and home measurements. Am J Hypertens 2001;14:74-6.

23. Viskoper R, Shapira I, Priluck R, Mindlin R, et al. Nonpharmacologic treatment of resistant hypertensives by device-guided slow breathing exercises. Am J Hypertens 2003;16:484-7.

24. Grossman E, Grossman A, Schein MH, Zimlichman R, Gavish B. Breathing control lowers blood pressure. J Hum Hypertens 2001;15:263-9.

25. Schein MH, Gavish B, Herz M, et al. Treating hypertension with a device that slows and regulates breathing: a randomised, double-blind controlled study. J Hum Hypertens 2001;15:271-8.

26. Ott NT, Shepherd JT. Vasodepressor reflex from lung inflation in the rabbit. Am J Physiol 1971;221: 889-95.

27. Furberg CD, Berglund G, Manolio TA, Psaty BM. Overtreatment and undertreatment of Hypertension. J Intern Med 1994;235:387-97.

28. Staessen JA, Byttebier G, Buntinx F, Celis H, O'Brien ET, Fagard R. Antihypertensive Treatment Based on Conventional or Ambulatory Blood Pressure Measurement. A randomized controlled trial. Ambulatory Blood Pressure Monitoring and Treatment of Hypertension Investigators. JAMA 1997; 278:1065-72.

29. Palatini P, Penzo M, Canali C, Dorigatti F, Pessina AC. Interactive action of the white coat effect and the blood pressure levels on cadiovascular complications in Hypertension. Am J Med 1997;103:208-16.

30. Verdecchia P, Schillaci G, Borgioni C, Ciucci A, Porcellati C. Prognostic significance of the white coat effect. Hypertension 1997;29:1218-24. 